\title{
Linda Hassall
}

\section{PERFORMANCE AND CLIMATE CHANGE: EVOKING THEATRICAL LANDSCAPES TO INVESTIGATE CLIMATE CHANGE}

\begin{abstract}
Australian landscapes both actual and perceptual can represent and enact space, and as such, can read, politicise and activate ways in which cultural geographies are imagined in contemporary theatre explorations (Carleton 2009). As a practice-led playwright researcher, I investigate theatrical landscapes to explore how cultural and environmental knowledge can effectively emerge through a play text or production. My creative research therefore contributes to debates in ecological and eco-critical fields through an analysis of how disappearing non-human nature may be attributed to cultural construction. The following discussion analyses a devised work which utilises an eco-critical framework to promote climate literacies in audience members -: Dust (Hassall 2015). The play explores and dismantles our Master Narratives - referred to within as 'miracles' - by exploring the negative impacts of human behaviour on non-human nature. The theatrical landscape is both physical and psychological, and generates the deconstruction of ideological perceptions of disappearing non-human nature as we know it. Dust aligns climate change themes with eco-critical debates and poses questions pertaining to contemporary custodianship of the landscape, environment and non-human nature. Further, the discussion provides an intersection between playwriting practice, politicised environmental themes and eco-critical dialogues, and identifies how contemporary environmental factors can stimulate climate change discussion in performance paradigms.
\end{abstract}

\section{Keywords: Performance; Australian Gothic; Climate Change}

\section{INTRODUCTION}

Theatre productions such as Dust can investigate the encounter between people, place and disappearing natural landscapes and habitats. Performance, therefore, can be a powerful cultural tool in shifting societal perceptions about exacerbated ecological issues (May 2007). As the risks of catastrophic climate change accelerate, there is a growing understanding of the role creative research can play in making sense of the ecological transformations we encounter (Wiseman 20I6). As theatre makers, we are able to respond to these issues by posing provocative questions to our audiences around the daily effects of climate change on our global environment. The following discussion analyses Dust through a politicised eco-critical lens. Dust places environmental criticism in a productive relationship with cultural expression. Produced at Metro Arts in Brisbane, Australia in September 2015, Dust played to approximately 500 audience members. With a cast of I8 graduating student performers in their final year showcase, Dust was developed as a reaction to increasing verifications of global warming that predict a $2 \mathrm{I}^{\text {st }}$ century in which we humans will come to terms with our relationship to the non-human world. A synopsis of Dust was outlined in Program Notes 2015, as:

Dust explores a hypothetical future time period - the Days After the Day of The Final Disaster. Set in a wasteland of humankind's own making, Dust explores the days and years after the day of the cataclysmic disaster that heralded the end of the world. 
Delivered from the perspective of a last surviving community eking out an existence in the apocalyptic wasteland, the play explores conflicting positions on the climate change crisis and questions why more wasn't done to avert The Final Disaster. Posing hypothetical experiences, Dust characters move in and out of time, through the chaos experienced by survivors - DUSTDRINKERS directly after the disaster to some remote point in the future where human beings - TRIBE - are on the very edge of extinction. Dust provokes dialogues about what might happen if something isn't done about climate change and poses questions to the audience about the ecological legacy we are leaving to those who come after us.

Switching between questions posed by future generations and stories left behind by us - those of us living in this time of ecological unrest - the play suggests that in these present days, perhaps in these our very last days, in the days leading into the end of days as we know -, we could have done more because we had the knowledge and the opportunity to do so. During this discussion, excerpts from Dust are included to support an eco-critical analysis of the performance text.

\section{ECO-CRITICAL THEATRE}

Rosendale (2002), suggests that a growing number of scholars are interested in expanding the purview of eco-critical practice by extending the definition of 'texts' beyond the written word. In this instance, eco-criticism is a useful analytical tool for the play as it aims to "expose the mythic underpinnings and consequent repercussions of unsustainable resource extraction and exploitation" (May 2007, p.IO4). Since colonisation, the unique Australian landscape has always defined our overarching cultural identity. The country's daunting, mythic presence has exerted power over the cultural psyche of the nation and informed who we are and how we behave. As such, the eco-critical framework applied in Dust poses an alternative reading of the contemporary Australian psyche in an age of mining expansion and consequent habitat depletion. Carducci
(2009) explains that a fictional representation of humankind is a primary topic of eco-criticism. Dramatic fiction, therefore, can effectively deal with humankind'shuman-kind's position vis -a -vis the natural world. Eco-critical theatre can investigate the way ecologies and environments can shape dramatic forms and stand at the edge of a vast open field of histories to be re-written, styles to re-discuss, and contexts of theatrical worlds to re-perceive (May 2007, pp.84-I03). Place, space, environments and ecologies may be considered from physical, perpetual, psychological and imagined perspectives. Embedded in Romantic traditions of Nature writing, eco-criticism has grown out of the literary analysis of landscape aesthetics (Hassall 20I7, p.I).

Eco-critical themes in Dust are explored through TRIBE characters who are living with the environmental legacy we, in, all likelihood, will leave behind. Sceneographic elements focused on evoking a desolate wasteland, devoid of colour or non-human nature, and were achieved this effect predominantly through LED lighting technologies. TRIBE language is depicted as having evolved in conjunction with the formation of the TRIBE communities. The language utilises an alternative grammatical structure, containing its own peculiar rhythms and tones of communication specific to TRIBE, to their behavior and their environment:

A desolate, apocalyptic world where there
is nothing of non-human nature and
where human beings are living on the
edge of extinction in TRIBE communities.

TRIBE MOTHER: These days are your last days, perhaps? Come Hell or High-water. Hell or High- water is comin'. Yes? Yes, it is. So, we is gonna give you a taste. A small taste of Hell and tiny sip of High water. Just in case. Just in case you'se might be interested in seeing what it might be like if you'se continue on. In these disaster days - and you surely might agree's with me that these are Disaster Days you is livin' - you is livin 'and breathin' history. Have you thought 'bout that? We's want you'se to ponder for a while on how's you is breathing your last on the edge of the apocalypse in these your days... in the days before 
the Dust. It's your legacy we is livin'. (Hassall 2015)

The opening scene above frames the work as an intimate conversation between performer and audience, and represents on one level how the audience is nominated almost as the antagonist of the play. It does so by suggesting that they could have done more to avert the disaster and therefore must take some responsibility in the climate crisis that they predict will unfold. Morton (2008) suggests creative works that examine eco-critical themes focus on a particular place, a particular moment, and a particular people or community in the construction of a fictional world. Dust sets up such a relationship between addresser and addressee, and establishes a point of contact between subjective expression (performance) and objective perception (spectatorship) in a space where performer and audience inhabit the same dimension. Audience objectivity is entrenched in the act of viewing the theatre event rather than in the actual experiencing of the events in reality. As such, the relationship acknowledges that the audience engage in the eco-critical inquiry, and on some level, consider the part they may have played in the ecological crisis that future generations must deal with:

Shaman is the leader of TRIBE. He has spiritual qualities that allow him to address the audience from the future.

SHAMAN: It was beautiful, yes? When you dust-drinkers could land-speak to the Earth and hear her warnings? No land-dreaming here now. No. None. Nevermore. Land-dreaming lost now under the dust. But you disbelieve. Yes? Don't be stupid blindeyes when we tells you now across time and distance and dust that soon you will turn to look at each other' look at what you did and did not do... an' you will be... gone ... 'Tis true. It is written in The Dust. (Hassall 20I5)

The communication of meaning across perceived space and time is central to TRIBE rituals wherein the characters attempt to make sense of why early 2Ist century humans seemingly ignored the climate crisis. The SHAMAN has the ability to move in and out of time using the stories left behind by TRIBE'S ancestors. TRIBE rituals are enacted through physical choreographic movement sequences, whereby the movements interpret what the SHAMAN has called forth from the dust. The rituals investigate notions of memory and legacy through reminiscences about once vibrant non-human nature and future experiences of the loss of it. As such, there is an interrelationship between eco-critical analysis and theme that utilises theatre's materiality to negotiate time, space and place, performative expression and audience experience. In doing so, it provokes audiences to consider questions concerning ecological wellbeing of species and spaces:

BIRDMAN recalls memories of an encounter with BIRDWOMAN. The past and the present overlap.

BIRD MAN: I saw her. A woman. A very pretty woman. Beautiful even. What struck me was that she was wearing lipstick. Red lipstick.

I saw her looking over the edge into the... into the what? What would you call it? Chasm? Emptiness? Hole? What do you call that sort of space? That space that's left behind when the earth starts to tear itself open? When place is gone and there is only space. What do you call that?

I was sort of concerned that she might fall in/So I yelled out to her.

\section{LADY! HEY LADY! BE CAREFUL}

I didn't go over to her, I just yelled out. Well yes. Yes. I was scared that it might open up more and I'd end up falling into the emptiness. So I yelled out to her. I yelled: 'Be careful'. And she turned and asked -

BIRDWOMAN: Did you see that?

BIRDMAN: 'What I said?'

BIRDWOMAN: The bird. The bird that fell out of the sky into the into the into the into the -

BIRDMAN And I said I hadn't seen any birds for quite some time. She said it was a shame that I hadn't seen it. She said -

BIRDWOMAN: O Shame... what a 
shame -

BIRDMAN: She said she thought it must be the last one. The last bird ever. The last bird we'll ever see. She asked me if I thought that was sad? I said I supposed I did. Before she asked me that I'd never really thought too much about birds, you know? Then she did it. She blew me a kiss. A great big red lip-sticked kiss. I felt that kiss cut through the dust and settle on my lips. Soft like. It had been a long time since anyone had kissed me like that. I was still feeling her kiss when she turned back to the hole and dived... graceful as all get out. Like a bird she was. She spread her arms wide like a bird on the wing and she dived.

(Hassall 2015)

In negotiating time, space, place and performative expression, Dust invites audiences to share in the environmental history unfolding and to acknowledge at least some responsibility in the escalation of the climate crisis.

\section{NON-HUMAN NATURE AS CULTURAL CONSTRUCTION}

As theatre and performance makers, we have the unique opportunity to perform our undeniable human predicament about our fragile ecological situatedness (May 2007). Dust enacts disappearing non-human nature as a result of cultural construction. Cultural construction in this instance refers to relevant social understandings that are embedded in wider cultural, political, economic and material contexts and which have impacted on non-human nature from various perspectives. Dust explores the legacy of cultural and industrial interventions in nonhuman nature's order. In doing so, the play makes a claim for sustainability awareness and action by promoting climate literacies in audiences. Non-human nature can be considered the protagonist - an active participant in the drama with the exacerbated weather conditions, failing ecosystems, rising sea levels generating the dramatic circumstance. Theatre technologies including non-toxic haze and desolate and/or ferocious soundscapes of weather conditions were utilised to create escalating levels of all- encompassing dust clouds. The human character is at the whim of non-human nature's response to the sustained mistreatment of her. The apocalyptic landscape - devoid of any natural life except for the last of human life suggests that landscape psychologically impacts on the characters' sense of themselves in space, time and place. Ultimately, it drives their questioning of us in this time, which in turn drives the narrative:

TRIBE characters enact one of their rituals associated with the Day of the Final Disaster.

TRIBE: The Dust she says:

You loved them carbon emissions. Yeeeeeeeeees.

She says:

You Goddamned loved them fossil fuel consumption. Yeeeeeeeees.

She says:

You was addicted to ozonesky depletion

And

Cancerous chemical dependencies

Praise God and Pass the Ammunition... Yeeeeeeeeees.

(Hassall 2015)

The play provokes questions concerning our participation in communities, about our willingness to respond to the material, industrial and ecological world and significantly, our willingness to respond to the crisis of cultural production and consumption. In Australia in 2015, The Guardian reported that Australia's carbon emissions had risen to the point where the Climate Council was calling for massive reductions in the coal mining industry. Dust responds to carbon escalation through ritual chorus behaviours:

SHAMAN: It is written that that big hole in the ozonesky got bigger and bigger, right above your heads. We's believe you'se were blindeyes - correct us if we's wrong - so didn't see that big space above your heads/and that's whys you'se did nothin'/cause you'se 
couldn't see it with your blindeyes/ and that's why that ozonesky burned up in a ultraviolet hole and them temperatures got real hot - burningscalding - hot Temperatures risin! Not your problem. Yes? We's understand how in them historyspeak you'se had no choice but to build thirsty cities. (Hassall 2015)

Theatre of this nature can respond to political discourse and as Punter (1982) suggests environmental transactions (as explored in Dust) [can] focus on the "user as much as on the environment itself" (p.3). In doing so, the theatre has the power to question what vision of nonhuman nature the play or performance authorises and/or makes legitimate, and for what purpose. The inherently visual nature of performance empowers us to explore politicised history, culture and communities through theatrical behaviors. The visual medium, therefore, offers theatre as point of cultural analysis, for while our messages may be political, theatre offers a way of seeing that sits outside purely political rhetoric (Deluca and Demno 2000). The liveness of the theatrical medium provides us with the unique opportunity of sharing visual stories with an audience and it is the visual live element that encourages the performer/audience relationship. Whilst the dramatic form and theatrical experience can offer political rhetoric as popular culture, it is the inherent ways of seeing human behaviors that can be unique:

A very thirsty man is wading in a pool of putrid water one month after the Day of the Final Disaster.

WATERBEARER: I came upon a pool. What once must have been a pool. You know a swimming pool. In-ground. I knew this because there was a blowup pool toy spinning in circles on the water at the bottom of the hole. A dolphin. A large blow up dolphin. Spinning. In the days before... before this day... I imagine that a child would have mounted that dolphin in the crystal blue waters of this backyard pool, shrieking with happiness as his brother or maybe his father tried to knock him from the dolphin into the water. It is the dolphin spinning on the thick water that causes me grief. There is barely any water left in that hole. What water sits on the bottom of what I imagine was once a pool is a colour that suggests it will be undrinkable. There is a bloated body. It too is an unthinkable colour. The corpse perhaps that of the father who would in better times pull his child from the dolphins back - is intermittently nudged by the spinning dolphin. I cannot take my eyes off that dolphin and it is the blow-up dolphin more than anything that makes me curse God. I move into the water and it feels oily and putrid. I try not to interfere with the dolphin as I collect water to boil. To boil and drink. (Hassall 2015)

The monologue explores the moral and ethical implications of a future culture deprived of clean water and asks an audience to consider how far might an individual go to survive. Whilst there are sub-textual elements contained within about species extinction, the dolphin is a dramatic device utilised to enable the characters' attention to be drawn away from the corpse. The excerpt further questions how human perceptions about the world, about who we are in the world, and about our relationship with popular master narratives including religion, might change after the ultimate climactic event.

Abram and Lien(20II), suggest thatagency of works such as this is understood in the performativity of non-human nature. When referring to Dust, it can be suggested that the agency of the work is in the uniqueness of the theatrical exchange whereby the loss of nature takes on "value, prestige and power" (p.3). In Dust, the loss of non-human nature articulates a perceived lack of successful human intervention in the climate crisis. The play's dramatic through-line, therefore, considers the repercussions of master-narratives relating to human activities that have impacted on the environment, including: green-house gas emission, unsustainable resource extraction, advanced industrialisation, and unsustainable practices.

\section{DISMANTLING MASTER NARRATIVES}

A master narrative is a transhistorical narrative 
that is deeply embedded in culture and in this discussion refers to human activities that have impacted on our environmental understanding. In the postmodern era, master narratives are being dismantled as accepted sociocultural knowledge is questioned (Lyotard 1984). Thematic analysis of Dust suggests that in the Anthropocene, the master-narratives no longer originate from individual communities as they did in the past, but are packaged by moneymakers who rewrite them focusing on global market economy (Dobrin 2013). Dust suggests that at a time when expanding human endeavours are being identified as the cause of endangering the integrity of all earth's resources and species, ecocritical performance can expose and dismantle the master narrative ideologies that support business as usual. Dust refers to these practices as miracles and investigates such concepts by questioning the negative impacts that arise:

TRIBE from their position in an almost extinct world of the future.

TRIBE: It was a time of magic?

A time of miracles?

A time of your magnificence. Yes?

Didn't reckon on them horsemen of your apocalypse ridin' through your lives and takin' away your belief in your God-given glory over all things, did ya? You were surprised. Yes? That that dirty dust devil Drought came in the days after the Day of The Final Disaster. Yes? Your thirst was impossible. Yes?

Your miracles, well... they just got out of hand. Yes, this we know. So sad your miracles, hey? No mind. Never mind. (Hassall 2015)

In an Australian context, the master narrative is closely linked to a national economy that is reliant on coal mining export which continues at the expense of the landscape, the natural habitat, and the Great Barrier Reef. Dust therefore questions our place in the world, and in our participation in Earth's escalating fragile ecologies. Responding to May's assertion that it is hubris to believe 'suffering' is only a human capacity $(2007,98)$, the theatrical aesthetic of Dust emerged from patterns of disappearing landmarks, ecological afflictions and human intervention in non-human nature. There is nothing left, and the scenographic environment suggests a hot, desolate wasteland, a world of dust and little else. These patterns then informed a dramatic imaginary wherein the characters attributed human characteristics to the natural world:

SHAMAN: The Earth she sorrowed during your time? Yes? She sorrowed. She bawled her bloody eyes out. Yes? Yes, she did. She was screaming. Yes? But you'se did nuthin'. No mind. Never mind.. maybe you'se just couldn't see with ya blindeyes. (Hassall 20I5)

Johns-Putra suggests that the impact of human activities on the environment, on species depletion, warming and climate change, will outlast human dimension and historical epochs (20I8, p.26). Theatre productions like Dust are becoming popular ways of responding to the Anthropocene - to the unprecedented human impact on the biosphere.

\section{CONCLUSION}

At this time in history, climate change predicts we are once again dwarfed by nature, by escalating natural disasters and climate change events. Dust poses a paradoxical relationship between perceptions of what is absent and what is present - between what is past and future, between the climate and disappearing landscapes and geographies (Hassall 20I7). Dust places a politicised version of 'nature memory' in the sublime position. It sets the memory of the pristine 'other' on a pedestal suggesting now is the time to nurture that which is disappearing and, as such, exemplifies how theatrical representation can contextualise eco-critical themes of loss and memory:

A day after The Final Disaster, TREEGIRL is slowly swinging a rope that hangs from a dead tree.

TREE-GIRL: This is... was my grandmother's tree. When I was a child I would climb up in its cool green branches and hide from my grandmother... I will think of this tree, my grandmother's tree. I will 
think about how I would hide up in its branches, in the summers when I was young and how in those endless summer days of Christmas holidays its branches would be heavy with fruit - mangoes - not them Bowen ones. Them stringy mangoes. Turpentine mangoes. My grandmother would make chutney out of them turpentine mangoes. Chutney, full of chunks of ginger and mangoes and swimming in brown sugar and vinegar. I won't think of chutney. Corn meat and chutney sandwiches. I won't think of sandwiches. I will think of the summers when I was young and believed in the magic of this tree and thought my grandmother would be alive forever. In the summer when I was young I used to think I could live in this tree. In the summer... in the summer near Christmas... when my grandmother wanted me to do things I didn't want to do. I used to pretend that I could live forever and ever in the tree when the school holidays stretched far into the future. I remember how the mangoes would fall to the ground and rot in the shade of the tree's cool green branches. I mustn't think of mangoes. When I was small there was an old swing strung from one of its branches. I recall how my feet would reach higher and higher toward heaven as my grandmother pushed me in the tyre swing. Higher and higher toward the blue sky... I mustn't think of blue sky... I won't. I will think about how loud I would shriek as I flew out into the sky. I must stop thinking of small things like mangoes and eggs and chutney and blue skies. I will focus on the rope. It's all I can see. I am too scared to look past the rope. To look past the rope into the distance and the dust. Soon... I will think about flying toward the sky and wonder if the rope will be strong enough to take my weight as I swing myself out toward the dust. (Hassall 2015)

Dust places climate change in the arena of cultural practice, and thereby utilises all aspects of the theatre's advantage to provide a unique platform to present, represent and engage in discourse around the very real climate and warming issues we have ahead of us. Dust achieved its important goal of increasing 'climate literacy' and provoking discussion, in students, artists and audiences by asking we consider our responses to working toward sustainable futures . Buckland (20I5, p.9) calls this time in which we are making art "an adventure of change" and posits that through making works (like Dust), we can use the relationship between art and science to make a better society - that we can take the big abstract ideas of climate change and make them into human stories - our stories.

\section{REFERENCES}

Abram, S. and Lien, M. E. (20II) Performing Nature at World's Ends. Ethnos 76 (I), I-I8.

Buckland, A. (2013) Novel Science: Fiction and the Invention of Nineteenth-Century Geology. Chicago, University of Chicago Press.

Carleton, S. (2009) Staging the North: Imagining and Performing an Australian Deep North. Unpublished doctoral dissertation. University of Queensland, St Lucia, Qld.

Carducci, V. (2009) Ecocriticism, Ecomimesis, and the Romantic Roots of Modern Ethical Consumption. Literature Compass 6 (3), 632-646. Online. Retrieved oI/o8/I8.

De Luca, K. M., and Demo, A.T. (2000) Imagining Nature: Watkins, Yosemite and the Birth of Environmentalism. Critical Studies in Media Communication I7 (3), 24I-260. DOI:IO.IO80/I5295030009388395.

Dobrin, A. (2013) Story-Telling is Necessary for Human Survival. Psychology Today, 7 August. Online. Retrieved from https://www.psychologytoday.com/us/blog/ am-i-right/20I3/storytelling-is-necessary-humansurvival,Io/o4/19.

Hassall, L. (20I7) Contemporary Theatrical Landscapes: The Legacy of Romanticism in Two Examples of Contemporary Australian Gothic Drama. In Green, S. and Hetherington, P. (eds.), Romanticism and Contemporary Writing: Legacies and Resistances: TEXT Special Issue [Online. Retrieved from http://www.textjournal.com.au/ speciss/issue4I/Hassall.pdf, I2/04/I9.

Hassall, L. (20I5) Dust. Written and directed by Linda Hassall at Sue Benner Theatre, September Season, Metro Arts, Brisbane City.

Johns-Putra, A. (2018) The Rest is Silence: Postmodern and Postcolonial Possibilities in Climate Change Fiction, Studies in the Novel 50 (I). Online. Retrieved from https: muse-jhu-edu.libraryproxy.griffith.edu.au/article/687645, IO/O4/I9. 
Lyotard, J. F. (1984) The Postmodern Condition: A Report on Knowledge. Translated by Geoff Bennington and Brian Massumi. Minneapolis, University of Minnesota Press.

May, T. (2007) Beyond Bambi: Toward a Dangerous Ecocriticism in Theatre Studies. Project Muse Theatre Topics I7 (2), 95-IIO. DOI:IO.I353/tt.2008.000I.

Morton, T. (2008) John Clare's Dark Ecology Studies in Romanticism 47 (2), I79-I93. Online. Retrieved from https://www-jstor-org.libraryproxy.griffith.edu.au/ stable/25602I4I, 28/09/I8.

Putner, D. and Byron, G.,eds. (2004) The Gothic. Oxford, Blackwell.

Rosendale, S. (2002) The Greening of Literary Scholarship: Literature, Theory, and The Environment. Iowa City, University of Iowa Press.

The Guardian Australian Edition (2015) Australia's Carbon Emissions Increasing, Government Report Shows, 26/12/I5. Online. Retrieved from https://www. theguardian.com/australia-news/2015/dec/26/australiascarbon-emissions-are-increasing-government-reportshows, I8/IO/I9.

Wiseman, J. (20I6) Art in a Harsh Climate: Pathways to a Just and Resilient Post-Carbon Culture'. In Abrahams, G., Gellatly, K. and Johnson, B. (eds.), $A R T+C L I M A T E=C H A N G E$. Melbourne, Melbourne University Press. 